\title{
Comparing nutrient reference concentrations in Nordic countries with focus on lowland rivers
}

\author{
Eva Skarbøvik (1), Jukka Aroviita, Jens Fölster, Anne Lyche Solheim, \\ Katarina Kyllmar, Katri Rankinen, Brian Kronvang
}

Received: 15 December 2019/Revised: 14 May 2020/Accepted: 14 July 2020/Published online: 15 September 2020

\begin{abstract}
Reference conditions of water bodies are defined as the natural or minimal anthropogenically disturbed state. We compared the methods for determining total phosphorus and total nitrogen reference concentrations in rivers in Finland, Norway and Sweden as well as the established reference conditions and evaluated the possibility for transfer and harmonisation of methods. We found that both methods and values differed, especially for lowland rivers with a high proportion of agriculture in the catchment. Since Denmark has not yet set reference conditions for rivers, two of the Nordic methods were tested for Danish conditions. We conclude that some of the established methods are promising but that further development is required. We moreover argue that harmonisation of reference conditions is needed to obtain common benchmarks for assessing the impacts of current and future land use changes on water quality.
\end{abstract}

Keywords Nordic $\cdot$ Nutrients $\cdot$ Reference conditions Rivers $\cdot$ EU Water Framework Directive

\section{INTRODUCTION}

Reference conditions (RC) represent a baseline for assessing the current ecological status of water bodies and can be quantified by, for instance, biological indicators and nutrient concentrations. The EU Water Framework Directive (WFD; EC 2000) defines RC as "no, or only very minor, anthropogenic alterations (...) for the surface water body types from those normally associated with that type

Electronic supplementary material The online version of this article (https://doi.org/10.1007/s13280-020-01370-4) contains supplementary material, which is available to authorised users. under undisturbed conditions". This definition leaves space for interpretation, especially in terms of the "very minor" deviation from undisturbed conditions (CIS Guidance 2003a). Stoddard et al. (2006) advocated that RCs in rivers should reflect minimally disturbed conditions or 'the condition of streams in the absence of significant human disturbance', but in lowland rivers such conditions are rarely found. In consequence, several methods have been advocated for establishing nutrient RCs (CIS Guidance 2003a; Stoddard et al. 2006; Poikane et al. 2019). In the presence of pristine water bodies, the preferred method to determine nutrient RCs is use of monitoring data on nutrients and nutrient-sensitive biological indicators. In the absence of pristine water bodies, a variety of other methods can be used, including models, data and information derived from historical records, expert judgement or a combination of these.

Determination of RCs is important since the RC concept serves different purposes (Stoddard et al. 2006; Carvalho et al. 2019; Fig. 1). Hawkins et al. (2010) noted that most of the published studies on ecological assessments during the last 25 years have depended on the determination of an "ecological benchmark for context". In the WFD, RC is also used as a basis for establishing the boundary between "good" and "moderate" ecological status (G/M boundary). This can be done either directly, for example, by multiplying the nutrient RC with a constant or by evaluating whether a suggested G/M boundary, which is often established from dose-response relationships using nutrientsensitive biology, is within a reasonable distance from the $\mathrm{RC}$, i.e. showing only "slight" deviation from RC (Bald et al. 2005; Carvalho et al. 2008, Huser and Fölster 2013, Lyche Solheim et al. 2008a, 2019). Biological data are often used to link tolerance levels for biological quality elements to nutrients or related stressors, such as the 


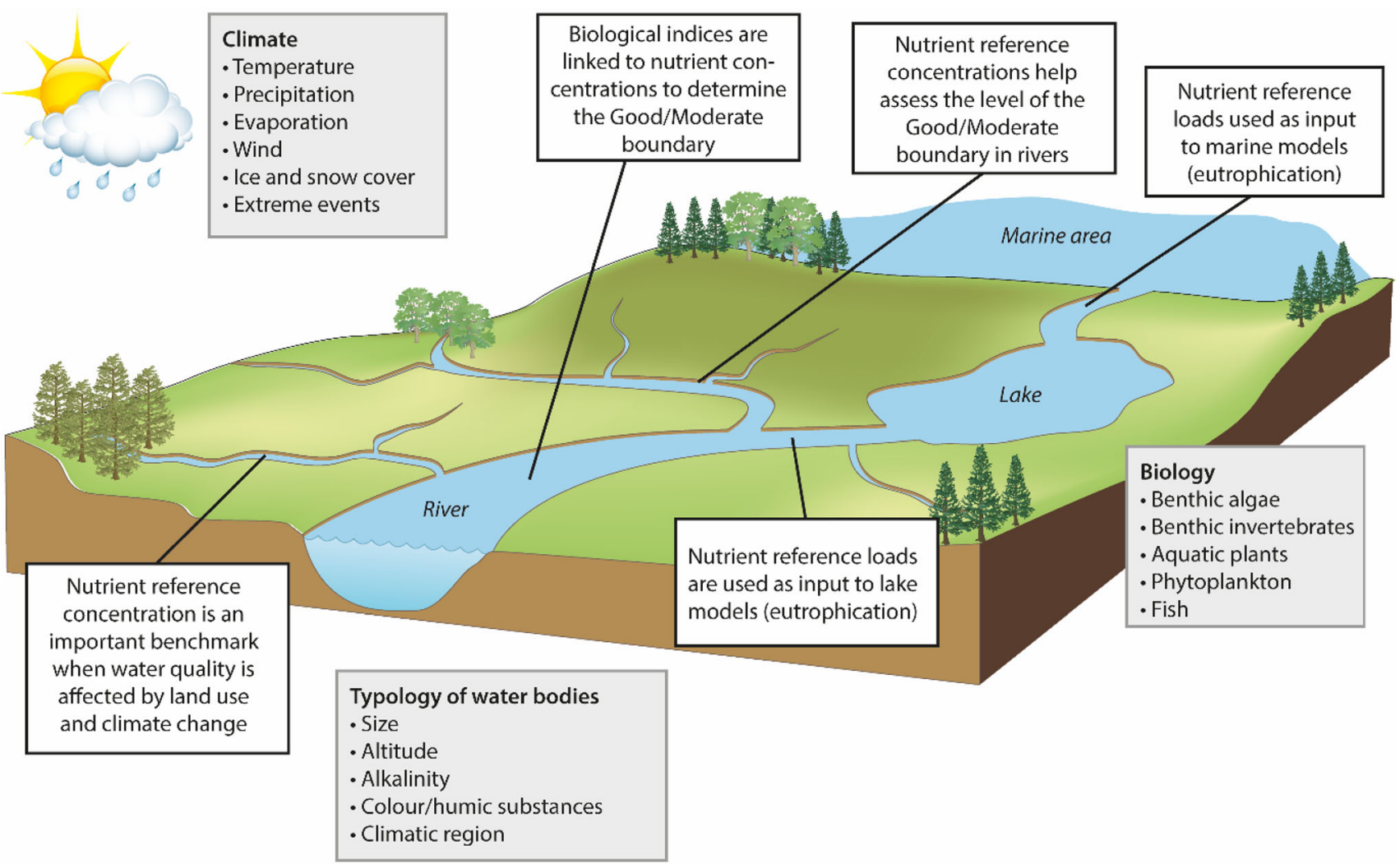

Fig. 1 Purposes of reference conditions illustrated in a river basin

Saprobic Diatom Index for diatoms (Rott et al. 2003), the Periphyton Index for trophic status for non-diatom algae (Schneider and Lindstrøm 2011), the Trophic Diatom Index for phytobenthos (Kelly and Whitton 1995) and the ASPT index for benthic invertebrates (Armitage et al. 1983). Moreover, riverine nutrient reference concentrations can be transferred to reference loads and serve as input data to lake models (Poikane et al. 2010) or marine models (Erichsen et al. 2017). When water bodies fail to achieve good status, it is necessary to implement mitigation measures and since these often are costly, determination of nutrient RCs and the critical G/M boundary are important also from an economic point of view (Phillips et al. 2018).

Nutrient RCs are relevant in yet another important context, namely as a benchmark for water quality during the coming land use changes caused by the expected transition to a bioeconomy (Hertel et al. 2012; O'Brien et al. 2017). This change may increase the need for biomass for various purposes, among others as a substitution for fossil fuels, which again may result in intensification of both forestry and agriculture (for a more detailed discussion of this topic, see Rakovic et al. (2020) and Marttila et al. (2020)). A related concern is that such land use changes may negatively affect freshwater quality and quantity (Ahtiainen and Huttunen 1999; Rosegrant et al.
2012). Harmonisation of Nordic methods, including nationally established RCs for nutrients, will be required to compare impacts of the land use changes across countries. As noted by Poikane et al. (2019), the G/M boundaries for European rivers vary widely among the EU countries, implying variations in the associated RC levels as well.

In this paper, we explored the established reference levels for the nutrients total phosphorus (TP) and total nitrogen $(\mathrm{TN})$ in three Nordic countries (Finland, Norway and Sweden) as well as the methods used for their determination. We also assessed to which degree the methods could be transferred to Denmark where national RCs for nutrients in rivers have not yet been established.

\section{METHODOLOGY}

We collected all relevant, available literature on the implementation of the WFD in the Nordic countries, including national guidelines, underlying reports and relevant international literature.

For river typology, we used the work of the so-called Geographical Intercalibration Groups (GIGs) that were established during the WFD Common Implementation Strategy (CIS) process to handle the intercalibration of the 
High/Good and Good/Moderate class boundaries for each biological quality element in each common intercalibration type (van de Bund 2009). Common criteria for water body types are based on geographical region, catchment size, altitude, alkalinity and organic matter (EC 2018). Most of Sweden and all of Finland and Norway belong to the "Northern GIG" and share five river types in lowland and mid-altitude regions. High-altitude rivers are not discussed in this paper since ample pristine water bodies exist within this category, and they are less likely to be impacted by the land use changes occurring due to the shift to bioeconomy. Denmark and the southernmost parts of Sweden are located within the Central/Baltic geographical region of Europe ("CB-GIG") and have two lowland river types in common. To these seven river types, we added one more common type-rivers draining clay-rich soils.

In Finland and Norway, RCs for nutrients in different river types are available in the most updated national guidelines (Direktoratsgruppen 2018; Aroviita et al. 2019). In Sweden, the national methodology is based on sitespecific predictive modelling, and calculation of ranges of reference values for each of the river types chosen for this study was therefore required.

In Denmark, RCs have not yet been set for rivers, and we therefore compared the following three methods to propose possible RC values for Danish rivers:

1. Direct use of water quality data from a monitoring programme applied in smaller Danish catchments with less than $10 \%$ agriculture (Kronvang et al. 2015). The conditions in these are comparable those defined by Stoddard et al. (2006) as "least disturbed conditions", i.e. the best available habitat conditions given today's state of the landscape. The streams were monitored for the first time in 2004/2005, and of these 16 were included in the Danish National Environmental and Nature Monitoring Programme and have since 2011 been monitored every 3rd year for daily discharge and monthly water chemistry parameters, including nutrient concentrations (map shown in Fig. 4c and supplementary material).

2. Modelling based on the Swedish model (see details in the below section on national methods). Two model versions, one without and one with agricultural impacts (Eqs. S3 and S4 in the supplementary material), were applied to the 16 rivers under (1).

3. Modelling based on the Norwegian model for rivers in clay-rich soils (see details in the below section on national methods). Since none of the small monitored streams were located in clay-rich soils, the Norwegian model was tested on the Uggerby River in northern Jutland where Quaternary marine clay soils underlie the aeolian sandy/sandy loam soils (map in Fig. 4d).

\section{DEFINITIONS OF REFERENCE CRITERIA FOR SELECTION OF NEAR-PRISTINE REFERENCE SITES IN THE NORDIC COUNTRIES}

The first step in the process of determining reference conditions is to identify true reference sites having nearpristine conditions. Where Denmark has not yet defined criteria for rivers, Finland and Norway have defined relatively similar reference criteria (Table 1). Sweden has divided the criteria definition into two categories depending on the amount of agriculture in the catchment. Thus, for rivers with more than $10 \%$ agriculture in the catchment, $\mathrm{RC}$ is defined as the runoff from tile-drained fallow land. This differs from Norway and Finland where RCs also in agricultural lowland rivers mainly are based on rivers draining unmanaged forests, peatlands or moorland.

\section{NATIONAL METHODS TO DETERMINE RCs}

Figure 2 presents an overview of the national methods used in each of the three Nordic countries. The methods varied less for river types for which pristine or near-pristine conditions exist (left part of the figure) than for river types for which pristine conditions are scarce (right part of the figure).

Table 1 National reference criteria for selecting reference sites in rivers in the four Nordic countries studied (van de Bund 2009; HaV 2017; Aroviita et al. 2019)

\begin{tabular}{lll}
\hline Country & Definition & Criteria \\
\hline Denmark & $\begin{array}{c}\text { Not yet defined on a national } \\
\text { level }\end{array}$ & \\
Finland & High status systems with & $<10 \%$ agriculture \\
& minimal anthropogenic & $<5 \%$ forestry \\
& pressure & $<0.8 \%$ urban land \\
Norway & Water bodies with little or no & $<10 \%$ agriculture \\
& anthropogenic pressure & Population density $<5$ \\
& & pe/km ${ }^{2}$ \\
& & No point source \\
& & pollution* \\
Sweden & In rivers with $<10 \%$ agricultural & $<25 \mu \mathrm{g} / \mathrm{l}$ of Tot-P \\
& soils & Unfertilised fallow on \\
& In rivers with $>10 \%$ agricultural & tile-drained land $* *$ \\
\hline
\end{tabular}

*These criteria were used to validate reference sites in the intercalibration of the reference values and high/good boundaries in the intercalibration process in Northern-GIG

**Based on the modelled leaching from unfertilised fallow on tiledrained land and under various climate conditions and soil types (Johnsson et al. 2016). This means that grazing, but not fertilisation or tillage is present under reference conditions 


\begin{tabular}{|l|l|}
\hline $\begin{array}{l}\text { River types for which pristine or near- } \\
\text { pristine catchments can be found. }\end{array}$ \\
$\begin{array}{l}\text { Finland, Norway: } \\
\text { reference } \\
\text { concentration } \\
\text { from direct } \\
\text { monitoring of } \\
\text { similar river types. }\end{array}$ & $\begin{array}{l}\text { Sweden: } \\
\text { Site-specific } \\
\text { modelling based } \\
\text { on water } \\
\text { chemistry and } \\
\text { altitude. }\end{array}$ \\
\hline
\end{tabular}

Finland, Norway:

TP and TN

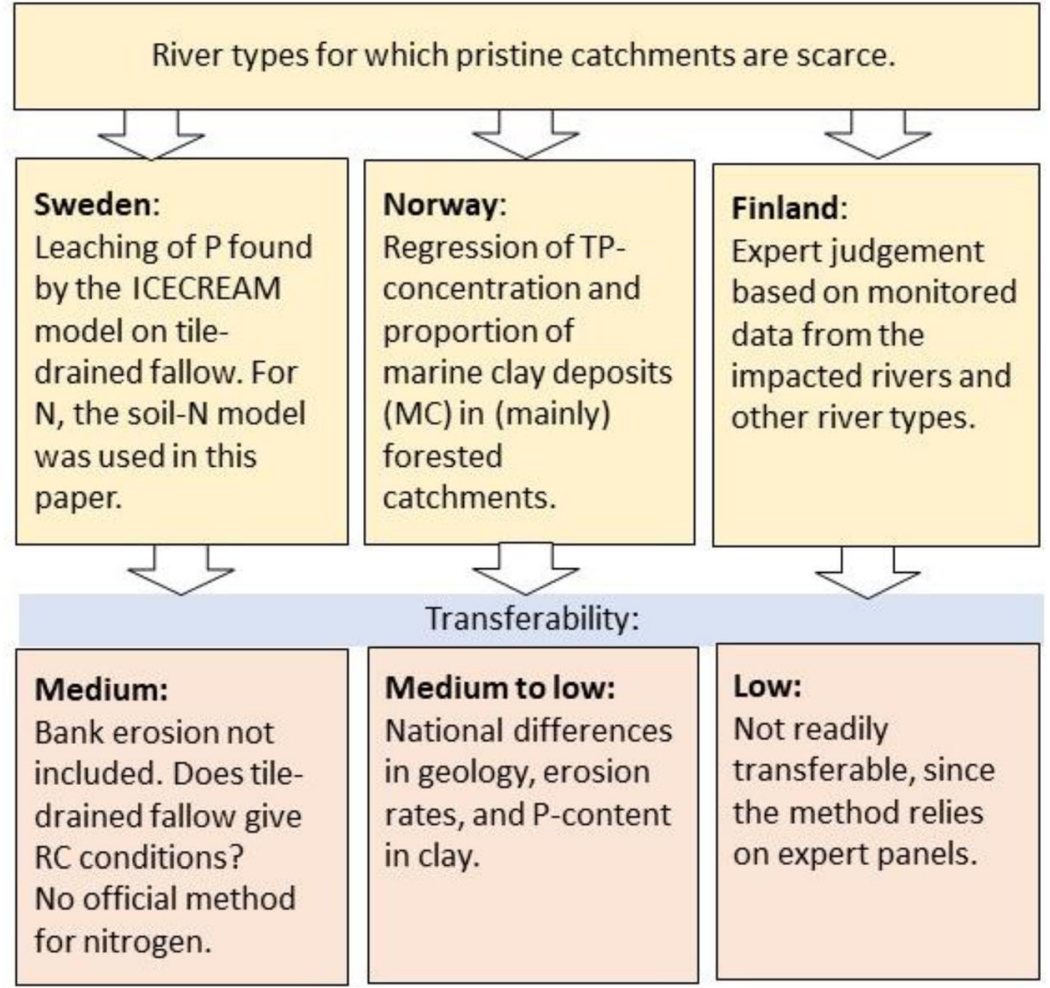

Sweden:

Leaching of $P$ foun

by the ICECREAM

model on tile-

drained fallow. For

$\mathrm{N}$, the soil- $\mathrm{N}$ mode

was used in this

paper.
Norway:

Regression of TP

concentration and

proportion of

marine clay deposits

(MC) in (mainly)

forested

catchments.

\section{Transferability:}

Medium to low:

tional difference

geology, erosion

rates, and $\mathrm{P}$-content

in clay.
Finland:

Expert judgement

based on monitored

data from the

impacted rivers and

other river types.

Fig. 2 Chart of the main methods used in the countries for two sets of river types-with pristine or near-pristine conditions (left) and without pristine or near-pristine conditions (right), including assessment of transferability between countries

A more thorough description of the national methods for defining reference conditions is given in the supplementary material section, both for river types with presence and absence of pristine or near-pristine catchments (principally lowland rivers with a high proportion of agricultural activity). Below, a short description is given of the methodologies used in the three countries.

In Finland, nutrient reference values were established based on expert judgement of monitoring data from minimally disturbed rivers of other river types and from data on disturbed rivers draining agricultural and clay-rich catchments. A national review panel evaluated the boundaries. Based on annual statistics, review panel work and tests with preliminary classification results, river type-specific High/Good status class boundaries for TP and TN were set as the 75th-90th percentiles of the nutrient concentrations among the reference or least disturbed rivers.

For Norwegian rivers draining clay-rich soils, a considerable part of the particulate phosphorus derives from the $\mathrm{P}$ in the clay-mineral apatite (Semb 1986), and the correlation in these rivers between suspended solids and TP is therefore usually good (Skarbøvik and Roseth 2014). A total of five streams draining clay-rich soils in catchments mainly covered by forest were used to produce a simple linear regression between the annual mean TP concentration and the proportion of the catchment area covered by marine clay (MC) (Lyche Solheim et al. 2008b; Eq. S1 in the supplementary material). MC was found by using superficial deposit maps without considering the depth of the clay deposits. Supposing $100 \%$ clay coverage, the maximum reference TP concentration would be $75 \mu \mathrm{g} / \mathrm{l}$, but as no Norwegian rivers with catchments larger than $10 \mathrm{~km}^{2}$ have such a high clay coverage, the maximum RC for TP was set to $40 \mu \mathrm{g} / \mathrm{l}$ (Direktoratsgruppen 2018). Since nitrogen levels are not believed to be affected by the clay content, the $\mathrm{RC}$ for $\mathrm{TN}$ is the same as that for national lowland river types that are humic and have medium to high calcium contents.

Sweden used predictive modelling to set TP reference conditions in rivers. The model used is a linear regression of TP as a function of water colour value, non-marine $\mathrm{Ca}+\mathrm{Mg}$ and altitude for a dataset on monitored rivers with $<25 \mu \mathrm{g} / \mathrm{l}$ TP to avoid anthropogenic eutrophication (SEPA 2010) (Eqs. S2 and S3 in the supplementary material).

For rivers with more than $10 \%$ agricultural land in the catchment, results from the calculation of source apportioning of nutrient loads to the sea in the Swedish reporting to HELCOM were used (Ejhed et al. 2018). The modelled site-specific background root zone leaching, and for $\mathrm{P}$ also surface runoff, forms the basis for the reference value for the agricultural rivers, which is calculated as an area- 
Table 2 RCs of TP and TN ( $\mu \mathrm{g} / \mathrm{l})$ for five common Nordic river types defined by the Northern GIG, and rivers draining clay-rich soils. n.d.: Not determined

\begin{tabular}{|c|c|c|c|c|c|c|c|}
\hline \multirow[t]{3}{*}{ Type } & \multirow[t]{3}{*}{ River characteristics } & \multicolumn{6}{|c|}{ Range of TP and TN reference levels $(\mu \mathrm{g} / \mathrm{l})$} \\
\hline & & \multicolumn{2}{|l|}{ Norway } & \multicolumn{2}{|c|}{ Finland $^{\mathrm{a}}$} & \multicolumn{2}{|l|}{ Sweden } \\
\hline & & $\mathrm{TP}$ & $\mathrm{TN}$ & $\mathrm{TP}$ & $\mathrm{TN}$ & $\mathrm{TP}$ & $\mathrm{TN}^{\mathrm{b}}$ \\
\hline R-N1 & Small lowland siliceous, moderate alkalinity & $9(1-15)$ & $275(1-425)$ & $<15$ & $<335$ & $10(6-14)^{\mathrm{c}}$ & $306(153-870)^{\mathrm{c}}$ \\
\hline $\mathrm{R}-\mathrm{N} 3$ & Small/medium lowland organic & $9(1-17)$ & $275(1-425)$ & $<20$ & $<450$ & $12(9-19)$ & $424(309-692)$ \\
\hline R-N4 & Medium lowland siliceous, moderate alkalinity & $9(1-15)$ & $275(1-425)$ & $<15$ & $<335$ & $9(5-14)^{\mathrm{c}}$ & $337(136-573)^{\mathrm{c}}$ \\
\hline R-N5 & Small mid-altitude siliceous & $5(1-8)$ & $150(1-250)$ & $<15$ & $<335$ & $4(3-6)$ & $147(100-210)$ \\
\hline R-N9 & $\begin{array}{l}\text { Small/medium mid-altitude silicious, } \\
\text { low alkalinity, organic (humic) }\end{array}$ & $8(1-13)$ & $250(1-400)$ & $<20$ & $<450$ & $9(5-12)$ & $341(170-557)$ \\
\hline Clay rivers & Lowland Clay-rich & $20-40^{\mathrm{d}}$ & 325 & $<40$ & n.d. & $8-30$ & $290-775$ \\
\hline
\end{tabular}

${ }^{\mathrm{a}}$ For Finland, the values represent the upper value in nutrient concentration range in RCs (High/Good status class boundary)

${ }^{b}$ Non-official data based on a suggestion from Fölster and Djodjic (2015)

${ }^{c}$ R-N1 and R-N4 in Sweden: No clear-water rivers found within those types in the dataset. Reference values calculated from corresponding humic types with colour set to a random value with the same distribution of other clear types with data

${ }^{\mathrm{d} D e p e n d i n g ~ o n ~ m a r i n e ~ c l a y ~ c o v e r a g e, ~ s e e ~ t e x t ~ f o r ~ e x p l a n a t i o n s ~}$

weighted average of the two reference values (Eq. S4 in the supplementary material).

Sweden has no official RCs for $\mathrm{N}$ in fresh water, but a similar method as for P has been suggested by Fölster and Djodjic (2015) and is used in this paper. This method involves a regression model for non-agricultural land that was developed from total carbon and nitrogen deposition values (Eq. S5 in the supplementary material).

\section{NUTRIENT RCS IN NORDIC GIG RIVER TYPES IN FINLAND, NORWAY AND SWEDEN}

For the five Nordic GIG river types, both TP and TN RC levels were relatively similar in the three countries, considering that the Finnish values represent the High/Good boundaries for water quality (Table 2). Higher deviations between the countries were found for the rivers draining clay-rich soils (as shown in Fig. 3a). Finland has set the High/Good boundary for TP at $<40 \mu \mathrm{g} / \mathrm{l}$, while the RCs of Norway and Sweden are based on regression analyses of TP concentrations and the catchments' coverage of, respectively, clay-rich soils (NO) and agricultural land (SE). Figure $3 \mathrm{~b}$ shows the data from five smaller forested streams that constitute the Norwegian basis for the linear regression $\left(R^{2}: 0.3\right)$, whereas Fig. $3 c$ shows the Swedish data from streams in tile-drained fallow for which a power equation regression gave the best correlation $\left(\mathrm{R}^{2}: 0.5\right)$. As shown, the correlations are poor, especially for the Norwegian data set where also the number of rivers is few, thereby adding to the uncertainty. An attempt to increase the number of rivers was done in 2014-2016, but the monitored streams had very steep slopes, which gave very high suspended sediment and total phosphorus concentrations (Skarbøvik, unpublished material). Hence, these data were not used in the revision of the national classification guidelines in 2018 (Direktoratsgruppen 2018).

\section{NUTRIENT RCS IN CENTRAL/BALTIC GIG LOWLAND RIVER TYPES IN DENMARK AND SWEDEN}

Table 3 shows the nationally agreed RCs for TP in the Central/Baltic GIG river types in Sweden, the values for TN being calculations based on Fölster and Djodjic (2015). The Danish RCs for nutrients were estimated based on the three methods outlined in the Methods section (direct monitoring, the Swedish model and the Norwegian regression equation for clay-rich catchments). The results revealed the following:

The actual data from the 16 Danish streams in least disturbed conditions had considerably higher TP concentrations than when using the Swedish model (Fig. 4a; 1st and 2nd bars, respectively). The Swedish method accounts for leaching of dissolved $\mathrm{P}$ but excludes input of particulate $P$ caused by natural bank erosion. However, as bank erosion as a P source is important in lowland Danish streams (Kronvang et al. 2012), this was accounted for by adding the concentration of particulate P (average: $18 \mu \mathrm{g} / \mathrm{P}$ ) in the 16 catchments to the original output from the Swedish model. The resulting TP concentrations (Fig. 4a, 3rd bar) were closer to the monitoring results, but large differences remained for several streams. This is especially true for 

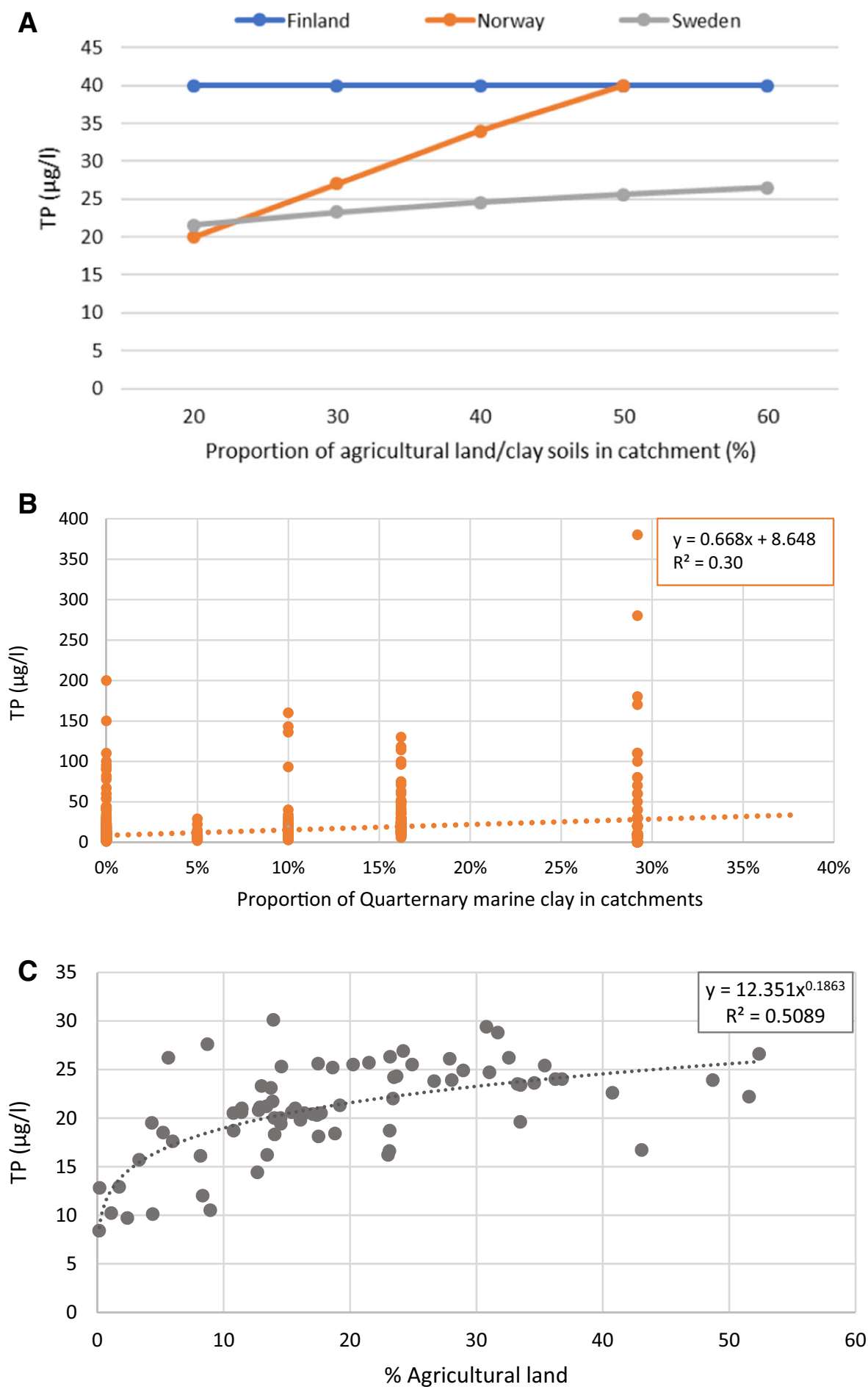

Fig. 3 Comparison of RCs for TP in Finland, Norway and Sweden (a); the Norwegian (b) and the Swedish (c) data basis for setting RCs in clayrich soils and agricultural lands, respectively. Note that the Finnish value represents the upper value in RC nutrient range (High/Good status class boundary) 
Table 3 Average concentration levels of Total P and Total N monitored in lowland Danish streams ( \pm SD), and modelled concentrations using Swedish models for total N and P RC, as well as concentrations with minimal agricultural impacts, for the two broad Central /Baltic GIG types R-C1 and R-C6; and rivers with high proportion of clay soils assessed with the Norwegian method. n.d.: Not determined

\begin{tabular}{|c|c|c|c|c|c|c|c|c|c|}
\hline \multirow[t]{3}{*}{ Type } & \multirow[t]{3}{*}{ River characteristics } & \multicolumn{3}{|c|}{$\begin{array}{l}\text { Denmark using monitoring of least } \\
\text { disturbed catchments (LDC) }{ }^{\mathrm{a}}\end{array}$} & \multirow{2}{*}{$\begin{array}{l}\text { Denmark by } \\
\text { Norwegian } \\
\text { method } \\
\text { TP }\end{array}$} & \multicolumn{2}{|c|}{$\begin{array}{l}\text { Denmark by } \\
\text { Swedish method }\end{array}$} & \multicolumn{2}{|l|}{ Sweden } \\
\hline & & No. of stations & $\mathrm{TP}$ & $\mathrm{TN}$ & & $\mathrm{TP}^{\mathrm{b}}$ & $\mathrm{TN}^{\mathrm{b}}$ & $\mathrm{TP}$ & $\mathrm{TN}^{\mathrm{c}}$ \\
\hline & & & $\mu \mathrm{g} / \mathrm{L}$ & & & & & & \\
\hline $\mathrm{R}-\mathrm{C} 1$ & $\begin{array}{l}\text { Small lowland } \\
\text { siliceous sand }^{\mathrm{d}}\end{array}$ & 6 & $79 \pm 43$ & $805 \pm 384$ & & $14-18$ & 374-2015 & $21(11-29)$ & $428(272-653)$ \\
\hline R-C6 & $\begin{array}{l}\text { Small lowland } \\
\text { calcareous }^{\mathrm{d}}\end{array}$ & 8 & $57 \pm 32$ & $1202 \pm 404$ & & $12-14$ & $313-1095$ & $22(16-30)$ & $384(273-527)$ \\
\hline Clay rivers & Lowland; Clay-rich & - & n.d. & n.d. & $10-30^{\mathrm{e}}$ & $12-32$ & $244-693$ & $8-30$ & $290-775$ \\
\hline
\end{tabular}

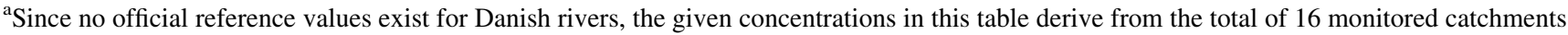
in 2011 of which the 14 could be placed in one of the types and correspond to Stoddard et al. (2006)'s least disturbed conditions (LDC)

${ }^{b}$ The low concentration value is the true reference concentration and the high value is when allowing for a minimal pressure from low intensity agriculture in the catchment; both values are calculated with the Swedish model (Eqs. S3 and S4 for TP and S5 for TN)

${ }^{\mathrm{c}}$ Non-official data based on a suggestion from Fölster and Djodjic (2015)

${ }^{\mathrm{d}}$ Information on substrate and width should be known for this typology, but is not

${ }^{\mathrm{e}}$ The span is explained by either using $41 \%$ clay coverage (including lower soil layers) or just $10 \%$ coverage (only including the surface layers)

streams located in the Jutland draining windblown sandy areas showing a high proportion of particulate $\mathrm{P}$ (streams No. 1, 2 \& 9 in Fig. 4), and one stream on Zealand draining peat areas and having high proportion of dissolved $\mathrm{P}$ (stream No. 12 in Fig. 4) (supplementary material). It should also be considered that other sources of nutrients may occur in the monitored catchments, such as sewage from cottages and scattered dwellings. In the last step, RCs further downstream the Danish river systems were estimated by adding modelled inputs of dissolved $\mathrm{P}$ from anoxic groundwater (Kronvang et al. 2007) (Fig. 4a; 4th bar).

For TN, the monitoring results gave lower RCs than the Swedish model for sandy catchments, whereas the monitoring and model results were more similar for loamy catchments (Fig. 4b; 1st and 2nd bars, respectively). The Danish sandy catchments often have a primary groundwater aquifer where substantial denitrification can take place below the redox zone (Højbjerg et al. 2015), and the standard retention factor in the Swedish model may therefore be too low (supplementary material). More comparable RCs for TN were obtained when the Swedish modelled $\mathrm{N}$ retention was substituted with the locally estimated $\mathrm{N}$ retention for the Danish catchments (Fig. 4b; 3rd bar). However, a major deviation was found for one stream (No. 8,S), probably because its catchment has a very low model-estimated $\mathrm{N}$ retention factor (0.09) (supplementary material). In the last step, $\mathrm{N}$ retention in surface waters (rivers and lakes) further downstream towards the coast was included to represent the total $\mathrm{N}$ concentration in rivers when they enter coastal waters (Fig. 4b). TN concentrations in the downstream rivers were in most cases considerably lower than in upstream 1st order streams (Fig. 4b; 4th bar).

The Norwegian regression between TP and the proportion of marine clay in the catchments (Eq. S1 in the supplementary material) was tested for River Uggerby $\left(348 \mathrm{~km}^{2}\right)$ situated in a clay-rich catchment in northern Denmark since none of the 16 small catchments were located on clay soils. River Uggerby has a high average suspended sediment concentration of $20-30 \mathrm{mg} / \mathrm{l}$ (Thodsen et al. 2019), suggesting that bank erosion may be considerable. Quaternary marine clay covers $41 \%$ of the catchment, but since there are aeolian deposits on top, less than $10 \%$ of the clay is found in the surface layers. This gave rise to the two assumptions that either the river bed had eroded into most of the marine clay layers $(=41 \%$ coverage), yielding an RC of $30 \mu \mathrm{g} / \mathrm{lP}$, or the river was only affected by the surface soils (as presumed in Norway), yielding an RC of $10 \mu \mathrm{g} / \mathrm{l} \mathrm{TP}$. This illustrates the fact that differences in geology complicate a direct transfer of the Norwegian method to other countries.

\section{DISCUSSION}

The Nordic countries have chosen different methods to establish nutrient RCs in rivers, and whereas some of these methods are transferable to neighbour countries (modelling), others are not (expert judgement). The RCs for similar water types did not in general differ greatly between the countries, but the uncertainty is high, 

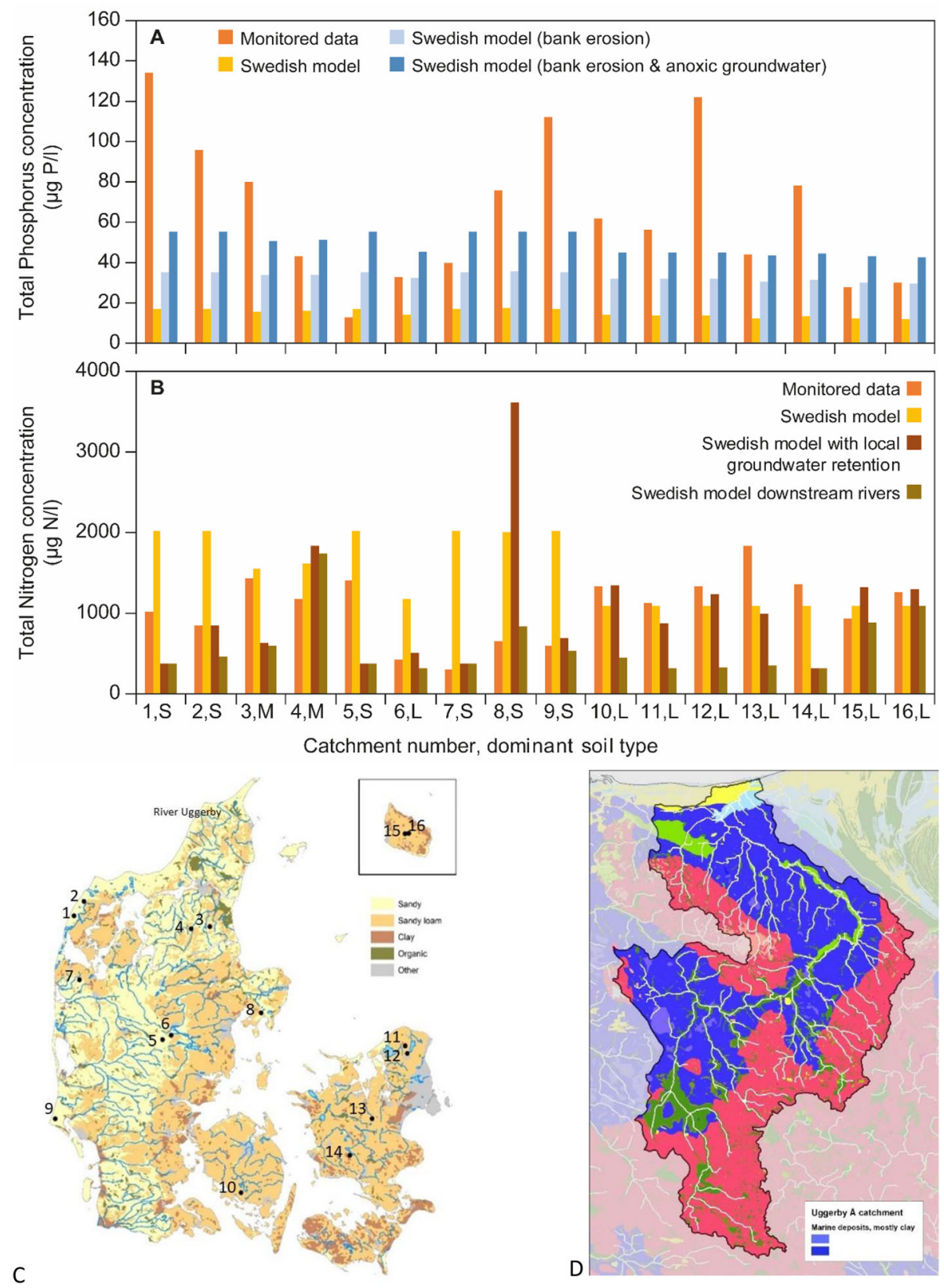

Fig. 4 Annual average TP (a) and TN concentrations (b) from the monitored 16 smaller 1st order streams draining natural catchments with less than $10 \%$ agriculture (stations shown in the soil map; c) and the catchment of River Uggerby with marine deposits in D. See text for explanations of the four bars. Dominant soil types: S: Sandy soils, corresponding to Small lowland siliceous sand in Table 3. L: Sandy loam, corresponding to Small lowland calcareous in Table 3. M: Mixed soils (not used in the calculation of RCs in Table 3)

especially for lowland rivers where the catchments are heavily impacted by agriculture and settlements. The uncertainty has resulted in a relatively wide range in RCs, and this will multiply if the RCs are used to find the G/M boundaries.

In the lowland regions, monitored data give but limited information, and must be combined with other methods, such as models, historical records, expert judgement or combinations of these. Several authors have noted that the choice of method can have significant impacts on the levels of nutrient thresholds. In a comparison of nutrient criteria between the EU member states, Poikane et al. (2019) found that expert judgement-based methods resulted in less stringent $\mathrm{G} / \mathrm{M}$ boundaries than data-driven approaches. Moreover, in a Canadian study of different nutrient target methods, empirical and modelling approaches provided less stringent results than ecological approaches (Chambers et al. 2008). Hawkins et al. (2010) reviewed over 1000 papers on this matter and observed that site-specific modelling was increasingly adopted due to their usually more 
accurate and precise determinations than the coarser estimates based on typology groups.

Of the four Nordic countries studied here, Sweden is the only one that has developed a site-specific model. Similar models, using altitude and alkalinity, have been developed in, for instance, the UK (UKTAG 2013) where RCs for TP in lowland rivers with low and high alkalinity were estimated to $19 \mu \mathrm{g} / \mathrm{l}$ and $36 \mu \mathrm{g} / \mathrm{l}$, respectively (Defra 2014). Interestingly, new knowledge of the relationship between $\mathrm{P}$ concentrations and the response of river plant communities has led to a revision with significantly lower RCs than those in the former 2009-guidance (UKTAG 2013, Defra 2014). This points to the importance of repeated evaluations of methods and RC levels based on new data on nutrient-sensitive biological quality elements. Empirical models have also been developed in the US (Smith et al. 2003) based on data from 63 minimally impacted basins describing the background yield of nutrients as functions of annual runoff, basin size, the atmospheric nitrogen deposition rate and region-specific factors such as geology and soil type. The authors suggested three classes of RCs for TP: 0-30, 30-60 and $>60 \mu \mathrm{g} / 1$, and for TN: $0-150,150-300$ and $>300 \mu \mathrm{g} / \mathrm{l}$.

Models have the advantage that they may be used across borders. However, testing the Swedish model on Danish streams made it clear that the model was adapted to the specific climatic variations, soils and natural catchment processes in Sweden, and modifications are therefore needed before its possible transfer to neighbouring countries. Among others, we suggest inclusion of natural bank erosion, a process that may result in high inputs of P-rich soils to rivers (Kronvang et al. 2012; Skarbøvik 2016), as well as a better consideration of site-specific anoxic groundwater contributions. Moreover, the importance of clay-rich soils should be better represented in the current Swedish model, for instance by further developing the Norwegian model to establish RCs in clay-rich rivers. Figure 5 illustrates the challenges inherent in determining RC from modelling, where Fig. 5a, b depicts pristine and impacted catchments, respectively, whereas Fig. 5c shows the nutrient sources and pathways in both natural and human-impacted catchments.

In the development of a new model, it is prudent to question if tile-drained fallow land should represent reference conditions, since more nutrients can leach from this land use type than from, for instance, forests (Ulén and Etana 2010). Certainly, a core challenge of setting RCs in the lowlands is that these areas have been cultivated for thousands of years, and the question is, therefore, what landscapes the 'true' RCs can be found in-forest, grassland, or agriculture? This is also an important question when using historical data to determine RCs. Denmark has not yet established nutrient RCs for rivers but the use of historical data from 1900 is discussed. However, at that time agriculture was widespread, $67 \%$ of the area being cropped, $8 \%$ being bare fallow and $22 \%$ being tile drained (Jensen et al. 2017). Other attempts to use historical data to determine nutrient concentrations in lowland European rivers have shown wide variations in ranges, with concentrations of TP varying between 9 and $56 \mu \mathrm{g} / \mathrm{l}$ and TN between 210 and $1316 \mu \mathrm{g} / \mathrm{l}$ (Hirt et al. 2014). Furthermore, an exercise using the model MONERIS to establish nutrient concentrations in 1880 in lowland rivers discharging to the German part of the North Sea and to the Baltic Sea catchment yielded average concentrations of TP and TN of $35 \mu \mathrm{g} \mathrm{P} / 1$ and $1500 \mu \mathrm{g} \mathrm{N} / 1$, respectively (Gadegast and Venohr 2015). Interestingly, the fact that most German agricultural streams and rivers have been heavily modified by channelling and other physical factors led to the decision to characterise many of these rivers as heavily modified water bodies. ${ }^{1}$ Hence, instead of setting RC levels they face the question of maximum ecological potential (CIS Guidance 2003b), but this entails the risk of allowing too liberal nutrient boundaries, potentially resulting in increased eutrophication.

Setting more accurate nutrient RCs in lowland rivers is important for both ecological and economic reasons. On average, $67 \%$ of the lowland rivers in Finland, Norway and Sweden have been reported to be in less than good ecological state (Lyche Solheim et al. 2019), ${ }^{2}$ and in Denmark, where almost all rivers are lowland rivers, $61 \%$ are reported to be in less than good state (see Footnote 1). The $\mathrm{G} / \mathrm{M}$ boundaries are often linked to the RCs, and uncertainty of these values can have severe impacts- too high RCs and G/M boundaries for nutrients may result in enhanced eutrophication and risks of harmful algal blooms (Carvalho et al. 2013), whereas too strict RCs and G/M boundaries may cause implementation of unnecessary nutrient reduction measures with significant economic consequences (Davis et al. 2015, Phillips et al. 2018). Less stringent RCs and G/M boundaries also entail the risk that managers may more readily allow new activities in a catchment such as intensified forestry or agriculture. For reasons such as these, various authors have questioned if the process of estimating RCs is rather policy-driven than based on science (Moss 2008, Bouleau and Pont 2015), supporting the argument that the methodologies for finding RCs should be transparent and harmonised. In the Nordic countries studied here, the RCs were set relatively early after the implementation of the WFD, and the uncertainty related to RCs for some lowland river types strongly points

\footnotetext{
1 Data from WISE dashboard: (https://www.eea.europa.eu/themes/ water/european-waters/water-quality-and-water-assessment/waterassessments/ecological-status-of-surface-water-bodies).

2 The proportion of clay rivers is not known.
} 


\section{A Natural (reference) catchment: Geology and soils}

Coarse moraine over bedrock

Clay, silt, sands and peat

$\begin{array}{lr}\text { Surface waters } & \text { Water quality } \\ \text { Wetland } & \text { Oligotrophic } \\ \text { Lake } & \text { Mesotrophic } \\ \text { Stream } & \text { Eutrophic } \\ \text { Climate } & \\ \text { Temperature } & \\ \text { Precipitation } & \end{array}$

B Human impacted catchment:
Land Use and Drainage
Landuse
Forestry
Agricultural land
Urban area
Scattered households
Artificially drained land
Nature reserve
Channelled rivers

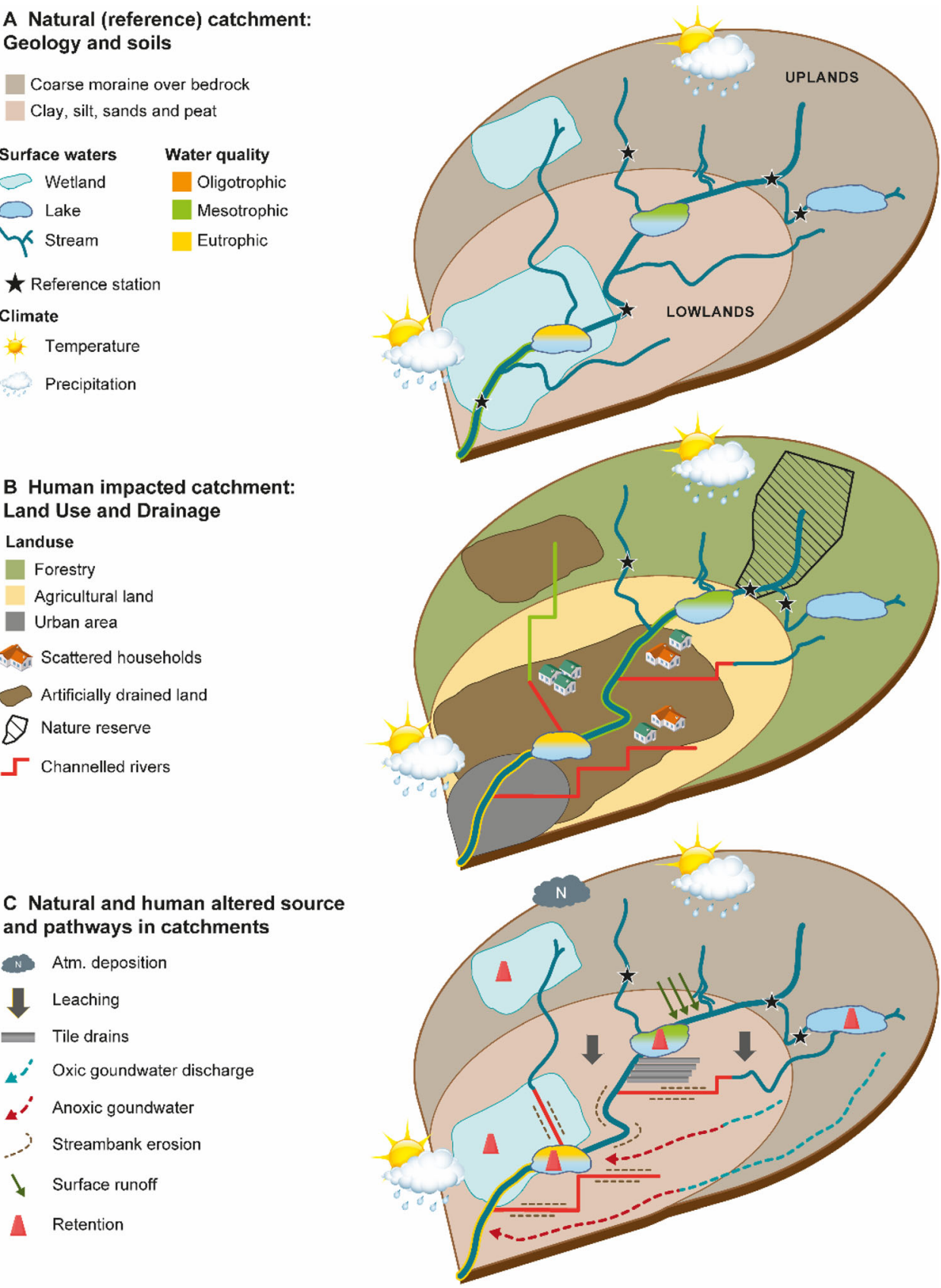

Fig. 5 Natural reference catchment (a) and catchment impacted by anthropogenic modifications (b), illustrating the challenge of finding pristine rivers in lowland areas; and sources and pathways of nutrients in both natural and impacted catchments (c)

to the need for introducing more harmonised and transparent methods.

\section{CONCLUSIONS}

The Nordic countries have chosen different methods to arrive at RCs, especially in lowland rivers where pristine conditions are rarely found. The resulting RCs are relatively comparable with some exceptions, but there is still a high degree of uncertainty in the RCs since all methods have their limitations. Establishment of RCs is a useful benchmark for assessing changes in rivers caused by land use and climate change. Therefore, RCs are becoming increasingly important, not least due to the expected land use changes in rural regions with the shift to bioeconomy. Except for Denmark, where the work on defining reference conditions is not yet finalised, establishment of reference conditions in the Nordic countries was completed in the early years after implementation of the WFD. Our findings 
strongly suggest the need for collection and use of new evidence data as well as development of sound models that incorporate regional catchment characteristics and processes. Preferably, a common model should be developed, taking into consideration all relevant processes in both natural catchments and catchments modified by human activities for centuries.

Acknowledgements Open Access funding provided by Norwegian Institute of Bioeconomy Research. This paper was supported by the Nordic Centre of Excellence 'BIOWATER', funded by NordForsk under Project No. 82263. We thank Tinna Christensen for graphical design and Anne Mette Poulsen for language assistance (Aarhus University, Denmark).

Open Access This article is licensed under a Creative Commons Attribution 4.0 International License, which permits use, sharing, adaptation, distribution and reproduction in any medium or format, as long as you give appropriate credit to the original author(s) and the source, provide a link to the Creative Commons licence, and indicate if changes were made. The images or other third party material in this article are included in the article's Creative Commons licence, unless indicated otherwise in a credit line to the material. If material is not included in the article's Creative Commons licence and your intended use is not permitted by statutory regulation or exceeds the permitted use, you will need to obtain permission directly from the copyright holder. To view a copy of this licence, visit http://creativecommons. org/licenses/by/4.0/.

\section{REFERENCES}

Ahtiainen, M., and P. Huttunen. 1999. Long-term effects of forestry managements on water quality and loading in brooks. Boreal Environment Research 4: 101-114.

Armitage, P.D., D. Moss, J.F. Wright, and M.T. Furse. 1983. The performance of a new biological water quality score system based on macroinvertebrates over a wide range of unpolluted running-water sites. Water Research 3: 333-347.

Aroviita, J., S. Mitikka and S. Vienonen (eds.) 2019. Status classification and assessment criteria of surface waters in the third river basin management cycle. Reports of the Finnish Environment Institute 37/2019: 1-177. (in Finnish) http://hdl. handle.net/10138/306745.

Bald, J., A. Borja, I. Muxika, J. Franco, and V. Valencia. 2005. Assessing reference conditions and physico-chemical status according to the European Water Framework Directive: A case-study from the Basque Country (Northern Spain). Marine Pollution Bulletin 12: 1508-1522.

Bouleau, G., and D. Pont. 2015. Did you say reference conditions? Ecological and socio-economic perspectives on the european water framework directive. Environmental Science \& Policy 47: 32-41. https://doi.org/10.1016/j.envsci.2014.10.012.

Carvalho, L., A. Solimini, G. Phillips, M. van den Berg, O.-P. Pietilainen, A. Lyche Solheim, S. Poikane, and U. Mischke. 2008. Chlorophyll reference conditions for European lake types used for intercalibration of ecological status. Aquatic Ecology 42: 203-211.

Carvalho, L., C. McDonald, C. de Hoyos, U. Mischke, G. Phillips, G. Borics, S. Poikane, B. Skjelbred, et al. 2013. Sustaining recreational quality of European lakes: minimizing the health risks from algal blooms through phosphorus control. Journal of Applied Ecology 50: 315-323. https://doi.org/10.1111/13652664.12059.

Carvalho, L., E.B. Mackay, A.C. Cardoso, A. Baattrup-Pedersen, S. Birk, K.L. Blackstock, G. Borics, A. Borja, et al. 2019. Protecting and restoring Europe's waters: An analysis of the future development needs of the Water Framework Directive. Science of the Total Environment 658: 1228-1238.

Chambers, P.A., C. Vis, R.B. Brua, M. Guy, J.M. Culp, and G.A. Benoy. 2008. Eutrophication of agricultural streams: Defining nutrient concentrations to protect ecological condition. Water Science and Technology 58: 2203-2210. https://doi.org/10.2166/ wst.2008.815.

CIS Guidance. 2003a. Guidance no. 10. Common Implementation Strategy Guidance document 10: River and lakes-Typology, reference conditions and classification systems. EC 2003: 94 pp.

CIS Guidance. 2003b. Guidance document 4: Identification and Designation of Heavily Modified and Artificial Water Bodies. EC 2003: 118 pp.

Davis, J., A.P. O'Grady, A. Dale, A.H. Arthington, P.A. Gell, P.D. Driver, N. Bond, M. Casanova, et al. 2015. When trends intersect: The challenge of protecting freshwater ecosystems under multiple land use and hydrological intensification scenarios. Science of the Total Environment 534: 65-78.

Defra. 2014. Water Framework Directive implementation in England and Wales: New and updated standards to protect the water environment. May 2014. Department for Environment, Food and Rural Affairs. https://assets.publishing.service.gov.uk/ government/uploads/system/uploads/attachment_data/file/ 307788/river-basin-planning-standards.pdf.

Direktoratsgruppen. 2018. Guidance 02:2018. National Guidance on Classification of environmental state in water. Direktoratsgruppen for gjennomføring av vanndirektivet. 222 pp. (in Norwegian). http://www.vannportalen.no/veiledere/.

EC. 2000. Directive 2000/60/EC of The European Parliament and of The Council; establishing a framework for Community action in the field of water policy. 23 October 2000.

EC. 2018. Commission Decision (EU) 2018/229 establishing, pursuant to Directive 2000/60/EC of the European Parliament and of the Council, the values of the Member State monitoring system classifications as a result of the intercalibration exercise and repealing Commission Decision 2013/480/EU. Official Journal of the European Union L47/1: $91 \mathrm{pp.}$

Ejhed, H., J. Tengdelius Brunell, E. Widén Nilsson, J. Hytteborn, H. Johnsson and K. Blombäck. 2018. PM method description of calculation of PLC6 pressure on new water body classification 2016-Version PLC6.5 SMED PM. (in Swedish).

Erichsen, A.C., K. Timmermann, J.P.A. Christensen, H. Kaas, S. Markager and F. Møhlenberg. 2017. Development of models and methods to support the Danish River Basin Management Plans. Scientific documentation. Aarhus University, Department of Bioscience and DHI: $191 \mathrm{pp}$.

Fölster, J. and F. Djodjic. 2015. Basis for assessing nitrogen in lakes and rivers. SLU, Vatten och miljö: Rapport 2015:12. (In Swedish).

Gadegast, M. and M. Venohr. 2015. Modeling of historical nutrient inputs and loads to derive nutrient reference values for Central European river basins. Bericht erstellt im Auftrag des NLWKN. Leibniz-Institut für Gewässerökologie und Binnenfischerei im Forschungsverbund Berlin e.V. Abteilung 1-Ökohydrologie Fachbereich Stoffeinträge und Stoffumsetzungen, Berlin: 39 pp. (in German).

HaV. 2017. Ocean and Water Authority's regulation on mapping and analysis of freshwater according to the regulation (2004:660) on management of water quality and environment. HVMFS 2017: 20. (In Swedish). 
Hawkins, C.P., J.R. Olson, and R.A. Hill. 2010. The reference condition: Predicting benchmarks for ecological and waterquality assessments. Journal of the North American Benthological Society 29: 312-343.

Hertel, T., J. Steinbuks and U. Baldos. 2012. Competition for Land in the Global Bioeconomy. Plenary paper prepared for Presentation at the meetings of the International Association of Agricultural Economists, Foz do Iguaçu, Brazil.

Hirt, U., J. Mahnkopf, M. Gadegast, L. Czudowski, U. Mischke, C. Heidecke, G. Schernewski, and M. Venohr. 2014. Reference conditions for rivers of the German Baltic Sea catchment: Reconstructing nutrient regimes using the model MONERIS. Regional Environmental Change 14: 1123-1138.

Huser, B.J., and J. Fölster. 2013. Prediction of reference phosphorus concentrations in Swedish lakes. Environmental Science and Technology 47: 1809-1815.

Højbjerg, A. L., J. Windolf, C.D. Børgesen, L. Troldborg, H. Tornbjerg, G. Blicher-Mathiesen, B. Kronvang, H. Thodsen and V. Erntsen. 2015. National nitrogen model. Catchment model for pressures and instruments: Method report. De Nationale Geologiske Undersøgelser for Danmark og Grønland-GEUS. 111 pp. (In Danish).

Jensen, P.N. (ed.). 2017. Estimation of Nitrogen Concentrations from root zone to marine areas around the year 1900. Aarhus University, DCE-Danish Centre for Environment and Energy, 126 pp. Scientific Report from DCE-Danish Centre for Environment and Energy No. 241. http://dce2.au.dk/pub/SR241.pdf.

Johnsson, H., M. Larsson, K. Mårtensson, and M. Hoffmann. 2002. SOILNDB: A decision support tool for assessing nitrogen leaching losses from arable land. Environmental Modelling \& Software 17: 505-517.

Kelly, M.G., and B.A. Whitton. 1995. The trophic diatom index: A new index for monitoring eutrophication in rivers. Journal of Applied Phycology 7: 433-444.

Kronvang, B., J. Bøgestrand, N.B. Ovesen, P. Nyegaard, and L. Troldborg. 2007. Background concentration of nitrogen and phosphorus in groundwater and surface water. In: Bøgestrand, J. (ed.) 2007. Water courses 2006. NOVANA. Danmarks Miljøundersøgelser, Aarhus Universitet. DMU no. 642: 96 pp. http:// www.dmu.dk/Pub/FR642.pdf. (In Danish).

Kronvang, B., J. Audet, A. Baattrup-Pedersen, H.S. Jensen, and S.E. Larsen. 2012. Phosphorus load to surface water from bank erosion in a Danish lowland river basin. Journal of Environmental Quality 41: 304-313.

Kronvang, B., J. Windolf, S.E. Larsen, and J. Bøgestrand. 2015. Background concentrations and loadings of nitrogen in Danish surface waters. Acta Agriculturae Scandinavica Section B 65: 155-163.

Lyche Solheim, A., S. Rekolainen, J. Moe, L. Carvalho, G. Phillips, R. Ptacnik, E. Penning, L. Toth, et al. 2008a. Ecological threshold responses in European lakes and their applicability for the Water Framework Directive implementation: Synthesis of lakes results from the REBECCA project. Aquatic Ecology 42: 317-334. https://doi.org/10.1007/s10452-008-9188-5.

Lyche Solheim, A., D. Berge, T. Tjomsland, F. Kroglund, I. Tryland, A.K. Schartau, T. Hesthagen, Borch, H. et al. 2008b. Suggested environmental targets for physical-chemical parameters in lakes and rivers, including clay-rich rivers and criteria for user interests. Supplement for the guidance on ecological classification. NIVA-Report 5708-2008. 79 pp. (In Norwegian).

Lyche Solheim, A., L. Globevnik, K. Austnes, P. Kristensen, J. Moe, J. Persson, G. Phillips, S. Poikane, et al. 2019. A new broad typology for rivers and lakes in Europe: Development and application for large-scale environmental assessments. Science of the Total Environment 697: 134043. https://doi.org/10.1016/j. scitotenv.2019.134043.
Marttila, H., A. Lepistö, A. Tolvanen, M. Bechmann, K. Kyllmar, A. Juutinen, H. Wenng, E. Skarbøvik, et al. 2020. Potential impacts of a future Nordic bioeconomy on surface water quality. Ambio. (This issue). https://doi.org/10.1007/s13280-020-01355-3.

Moss, B. 2008. The water framework directive: Total environment or political compromise? Science of the Total Environment 400: $32-41$.

O'Brien, M., D. Wechsler, S. Bringezu, and R. Schaldach. 2017. Toward a systemic monitoring of the European bioeconomy: Gaps, needs and the integration of sustainability indicators and targets for global land use. Land Use Policy 66: 162-171.

Phillips, G., M. Kelly, H. Teixeira, F. Salas, G. Free, W. Leujak, J.A. Pitt, A. Lyche Solheim, et al. 2018. Best practice for establishing nutrient concentrations to support good ecological status. JRC Science for Policy Report. EUR 29329 EN: 142 pp. https://ec. europa.eu/jrc/en/publication/eur-scientific-and-technical-researchreports/best-practice-establishing-nutrient-concentrations-supportgood-ecological-status.

Poikane, S., M.H. Alves, C. Argillier, et al. 2010. Defining chlorophyll-a reference conditions in European lakes. Environmental Management 45: 1286-1298.

Poikane, S., M.G. Kelly, F.S. Herrero, J.-A. Pitt, H.P. Jarvie, U. Claussen, W. Leujak, A. Lyche Solheim, et al. 2019. Nutrient criteria for surface waters under the European Water Framework Directive: Current state-of-the-art, challenges and future outlook. Science of the Total Environment 695: 133888. https://doi.org/ 10.1016/j.scitotenv.2019.133888.

Rakovic, J., M.N. Futter, K. Kyllmar, K. Rankinen, M.I. Stutter, J. Vermaat, and D. Collentine. 2020. Nordic Bioeconomy Pathways: Future narratives for assessment of water-related ecosystem services in agricultural and forest management. Ambio. (This issue). https://doi.org/10.1007/s13280-020-01389-7.

Rosegrant, M.W., C. Ringler, T. Zhu, S. Tokgoz and P. Bhandary. 2012. Water and food in the bioeconomy-challenges and opportunities for development. Plenary Paper prepared for presentation at the International Association of Agricultural Economists (IAAE) Triennial Conference, Foz do Iguaçu, Brazil.

Rott, E., E. Pipp, and P. Pfister. 2003. Diatom methods developed for river quality assessment in Austria and a cross-check against numerical trophic indication methods used in Europe. Algological Studies 110: 91-115.

Schneider, S., and E.A. Lindstrøm. 2011. The periphyton index of trophic status PIT: A new eutrophication metric based on nondiatomaceous benthic algae in Nordic rivers. Hydrobiologia 665: $143-155$.

Semb, G. 1986. Comparison of AL- and sodium carbonate soluble phosphorus in soil with $\mathrm{pH}$ over 6.6. Tidskrift for det norske jord-og myrselskap 5: 185-193. (In Norwegian).

SEPA. 2010. Status, potential and quality requirements for lakes, watercourses, coastal and transitional waters. Status, potential and quality requirements for lakes, watercourses, coastal and transitional waters. SEPA Handbook 2007:4; 421 pp.

Skarbøvik, E., and R. Roseth. 2014. Use of sensor data for turbidity, $\mathrm{pH}$ and conductivity as an alternative to conventional water quality monitoring in four Norwegian case studies. Acta Agriculturae Scandinavica Section B 65: 63-73.

Skarbøvik, E. 2016. Testing methods for quantification of bank erosion in clay-rich rivers, and the impact of bank erosion on phosphorus losses to water. VANN 01: 30-42. (In Norwegian, with English abstract).

Smith, R.A., R.B. Alexander, and G.E. Schwarz. 2003. Natural background concentrations of nutrients in streams and rivers of the conterminous United states. Environmental Science and Technology 37: 3039-3047. 
Stoddard, J.L., D.P. Larsen, C.P. Hawkins, R.K. Johnson, and R.H. Norris. 2006. Setting expectations for the ecological condition of streams: The concept of reference condition. Ecological Applications 16: 1267-1276.

Thodsen, H. et al. 2019. Water courses 2017. NOVANA. Aarhus University, DCE-Danish Centre for Environment and Energy, Scientific Report No. 306: 74 pp (in Danish). http://dce2.au.dk/ pub/SR306.pdf.

Ulén, B., and A. Etana. 2010. Risk of phosphorus leaching from low input grassland areas. Geoderma 158: 359-365.

UKTAG. 2013. Phosphorus standards for rivers. Updated Recommendations. August 2013. UK Technical Advisory Group, 14 pp. http://www.wfduk.org/sites/default/files/Media/UKTAG\%20Phosp horus\%20Standards\%20for\%20Rivers_Final\%20130906.PDF.

Van de Bund, W. 2009. Water Framework Directive Intercalibration Technical Report. Part 1: Rivers. European Commission report EUR 23838 EN/1-Joint Research Centre-Institute for Environment and Sustainability, https://doi.org/10.2788/23384: 136 pp.

Publisher's Note Springer Nature remains neutral with regard to jurisdictional claims in published maps and institutional affiliations.

\section{AUTHOR BIOGRAPHIES}

Eva Skarbøvik $(\bowtie), \mathrm{PhD}$, is Research leader for the Department of Hydrology and Water Environment at the Norwegian Institute of Bioeconomy Research (NIBIO). Her research interests include catchment hydrology, water quality and eutrophication.

Address: Norwegian Institute for Bioeconomy Research, NIBIO, P.O. Box. 115, 1431 As, Norway.

e-mail: eva.skarbovik@nibio.no

Jukka Aroviita, $\mathrm{PhD}$, is a senior research scientist at the Finnish Environment Institute (SYKE), Freshwater Centre, Water Information System Unit, and a docent in Aquatic Ecology at the University of Oulu, Finland. He is a freshwater ecologist with interest in how to develop accurate and sensitive bioassessment of streams and lake ecosystems.

Address: Freshwater Centre, Finnish Environment Institute, PO Box 413, 90014 Oulu, Finland.
Jens Fölster, $\mathrm{PhD}$, is an associate professor at the Swedish University of Agricultural Sciences. His research interests include environmental monitoring and water resources management related to acidification and eutrophication of water bodies.

Address: Department of Aquatic Sciences and Assessment, Swedish University of Agricultural Sciences, PO Box 7050, 75007 Uppsala, Sweden.

Anne Lyche Solheim, $\mathrm{PhD}$, is a senior researcher at the Section for Freshwater Ecology at the Norwegian Institute for Water Research (NIVA). Her research interests include eutrophication and climate change impacts on water quality, and ecological status of lakes and rivers.

Address: Norwegian Institute of Water Research, NIVA, Gaustadalléen 21, 0349 Oslo, Norway.

Katarina Kyllmar, $\mathrm{PhD}$, is a research leader at the Swedish University of Agricultural Sciences. Her research interests include environmental monitoring and assessment with focus on the small agricultural catchment scale.

Address: Department of Soil and Environment, Swedish University of Agricultural Sciences, PO Box 7014, 75007 Uppsala, Sweden.

Katri Rankinen, PhD, is a senior research scientist at the Finnish Environment Institute (SYKE). Her research interests include catchment modelling and the impacts of climate and land use change on nutrients in water bodies.

Address: Biodiversity Centre, Finnish Environment Institute, Latokartanonkaari 11, 00790 Helsinki, Finland.

Brian Kronvang, $\mathrm{PhD}$, is a professor at Department of Bioscience, Aarhus University. His research interests are catchment science and environmental management.

Address: Department of Bioscience, Aarhus University, Vejlsøvej 25, 8600 Silkeborg, Denmark. 